\title{
DELINEASI DAS DAN ELEMEN MODEL HIDROLOGI MENGGUNAKAN HEC-HMS VERSI 4.4
}

\author{
M. Baitullah Al Amin'), Mona F. Toyfur'), Widya Fransiska AF ${ }^{3)}$, dan Ayu Marlina ${ }^{4}$ \\ ${ }^{1,2)}$ Program Studi Teknik Sipil, Universitas Sriwijaya, Jl. Raya Prabumulih - Km 32 Indralaya, Ogan Ilir \\ ${ }^{3)}$ Program Studi Teknik Arsitektur, Universitas Sriwijaya, Jl. Raya Prabumulih - Km 32 Indralaya, Ogan Ilir \\ 4)Program Studi Teknik Sipil, Universitas Tridinanti Palembang, Jl. Kapten Marzuki No.2446 Kamboja, Palembang
}

\begin{abstract}
The watershed delineation process is needed and has an essential role in various water resource projects. This study aims to examine the GIS processing function embedded in the latest HEC-HMS software version 4.4 for the delineation of watershed and elements of the hydrological model. In comparison, watershed delineation was also carried out by using ArcGIS software. The area of study is the Bendung subbasin located in Palembang City, where terrain data used is a National DEM data with a spatial resolution of $8 \mathrm{~m}(0.27$ arc-second). The results showed that the boundaries and area of the watershed produced by HEC-HMS 4.4 and ArcGIS showed the same characteristics. The river network produced by the two software shows a slight difference even though the flow patterns are similar. It shows that the level of accuracy and quality of the delineation produced by the HEC-HMS 4.4 is excellent. Besides, elements of the hydrological model can be generated automatically which is not found in previous versions. It allows users to more quickly simulate detailed hydrological models with a large number of elements. Therefore, the use of GIS functions in HEC-HMS 4.4 must be encouraged for various analysis purposes in water resources projects.
\end{abstract}

Key Words: Bendung subbasin, DEM, GIS, hydrologic model, watershed delineation

\section{PENDAHULUAN}

Perangkat GIS (geographical information system) saat ini merupakan alat yang sangat membantu proses delineasi daerah aliran sungai (DAS). Hal ini disebabkan karena suatu DAS bersifat spesifik dan meliputi wilayah yang relatif luas sehingga dalam penentuan karakteristiknya diperlukan metode dengan akurasi yang tinggi, mudah untuk digunakan, dan biaya yang terjangkau (Gunawan, 2011). Dengan menggunakan perangkat GIS yang didukung data elevasi atau terrain yang baik akan dapat dihasilkan batas-batas berikut karakteristik suatu DAS yang kompleks secara akurat dan lebih mudah (Islam, 2004). Penggunaan GIS terbukti sebagai cara yang mudah dan akurat dalam pemodelan hidrologi dan seharusnya didorong dalam bidang teknik dan manajemen sumberdaya air (Bhatt \& Pandya, 2014).

Proses delineasi DAS sangat dibutuhkan dan mempunyai peran yang krusial dalam berbagai proyek di bidang sumberdaya air, yaitu secara spefisik pada tahap pemodelan hidrologi. Analisis ini dapat digunakan untuk keperluan prediksi banjir (Oleyiblo \& Li, 2010; Strapazan \& Petrut, 2017), simulasi hujan-aliran (Tassew, Belete, \& Miegel, 2019; Eljack, Elhag, \& Elsheikh, 2015), simulasi aliran lahar (Ilham, Prasetyo, \& Sabri, 2020), dan lain sebagainya.
Tingkat ketelitian delineasi dari suatu DAS bergantung pada tingkat akurasi dan resolusi data terrain atau digital elevation model (DEM) yang tersedia (Savant, Wang, \& Truax, 2002). Beberapa data DEM yang tersedia untuk wilayah seperti di Indonesia diantaranya seperti data SRTM (Shuttle Radar Topography Mission) dan ASTER GDEM (Advanced Spaceborne Thermal Emission and Reflection Radiometer - Global Digital Elevation Model). Tingkat akurasi delineasi DAS menggunakan data SRTM adalah lebih baik dibandingkan jika menggunakan data ASTER GDEM (Sutisna \& Putro, 2018). Disamping data SRTM dan ASTER GDEM, untuk wilayah Indonesia juga tersedia DEM Nasional (DEMNAS) yang tergolong baru dirilis oleh Badan Informasi Geospasial (BIG). Data DEMNAS ini merupakan integrasi data ketinggian yang meliputi data IFSAR (Interferometric Synthetic Aperture Radar) dengan resolusi $5 \mathrm{~m}$ dan ALOS PALSAR (Advanced Land Observing Satellite - Phased Array type L-band Synthetic Aperture Radar) yang beresolusi 11,25 m. Dengan kedua jenis data ini, DEMNAS mempunyai resolusi spasial sebesar 0.27 arc-second yang lebih baik dibandingkan data SRTM dengan resolusi spasial 1 arc-second (Iswari \& Kasih, 2018).

Perangkat HEC-HMS (Hydrologic Engineering Center-Hydrologic Modeling System) pertama kali dikembangkan oleh U.S. Army Corps of Engineers 
pada tahun 1967. Pada awal dikembangkan perangkat ini bernama HEC-1 (Oleyiblo \& Li, 2010). Sejak versi 2 perangkat ini berganti nama menjadi HEC-HMS yang telah berbasis grafis. Dalam perkembangannya banyak perbaikan dan penambahan fungsi-fungsi yang berguna dalam pemodelan hidrologi.

Seiring dengan perkembangan teknologi GIS, otomatisasi delineasi DAS dan elemen-elemen model hidrologi ikut dipertimbangkan. Perangkat HEC-GeoHMS (Geospatial Hydrologic Modeling Extension) kemudian dikembangkan pada tahun 2003. Perangkat ini dipasang sebagai ekstensi atau plugin yang disematkan dalam perangkat ArcGIS dengan tujuan memudahkan pengguna dengan pengalaman GIS yang terbatas (Flemming \& Doan, 2013). Ekstensi HEC-GeoHMS berakhir pada versi 10.2 yang kompatibel dengan ArcGIS 10.2. Pengembangan selanjutnya dilakukan dimana kapabilitas dari HEC-GeoHMS langsung disematkan ke dalam HEC-HMS versi terbaru. Hal ini akan mempersingkat waktu untuk proses delineasi DAS dan skematisasi elemen-elemen model hidrologi terutama untuk model yang sangat besar

(https://www.hec.usace.army.mil/confluence/hmsdo cs/hmsum/4.4/release-notes, diakses pada 20 April 2020).

Perangkat HEC-HMS 4.4 adalah versi terbaru yang dirilis pada 14 April 2020 lalu. Seperti yang telah disebutkan sebelumnya, perangkat ini telah dilengkapi dengan fungsi pemrosesan GIS dan akan terus dikembangkan di masa mendatang. Terdapat 12 fungsi GIS dalam HEC-HMS 4.4. Untuk keperluan delineasi, fungsi-fungsi GIS dibuat secara berurutan

(https://www.hec.usace.army.mil/confluence/hmsdo cs/hmsum/4.4/geographic-information/gis-menu, diakses pada 20 April 2020).

Penelitian ini bertujuan untuk menelaah fungsi pemrosesan GIS dalam proses delineasi DAS dan elemen model hidrologi yang disediakan pada HECHMS terbaru versi 4.4. Dengan demikian, dari hasil penelitian ini diharapkan dapat diperoleh gambaran mengenai tahapan, proses, dan hasil delineasi menggunakan perangkat tersebut.

\section{METODOLOGI}

Seluruh proses delineasi DAS menggunakan metode analisis GIS. Dalam penelitian ini, delineasi DAS dilakukan secara terpisah masing-masing pada HEC-HMS 4.4 dan ArcGIS 10.2.1. Hal ini dilakukan dengan tujuan untuk memperoleh perbandingan hasil di antara keduanya. Adapun perangkat ArcGIS merupakan perangkat umum yang sudah digunakan secara luas untuk keperluan analisis GIS.
Data utama yang digunakan untuk analisis adalah data model elevasi digital atau DEM. Dalam penelitian ini digunakan data DEM pada sub-DAS Bendung, yaitu salah satu wilayah drainase di Kota Palembang yang aliran sungainya bermuara ke Sungai Musi. Data DEM yang digunakan adalah DEM nasional yang diperoleh dari Badan Informasi Geospasial (BIG) dengan tingkat resolusi $8 \mathrm{~m} \times 8 \mathrm{~m}$.

Secara berurutan tahapan dalam penelitian ini adalah: 1) persiapan data DEM, 2) delineasi DAS di HEC-HMS 4.4, 3) delineasi DAS di ArcGIS, 4) delineasi DAS dan elemen model hidrologi, dan 5) komparasi hasil dan pembahasan seperti yang diberikan dalam bagan alir (Gambar 1) di bawah ini.

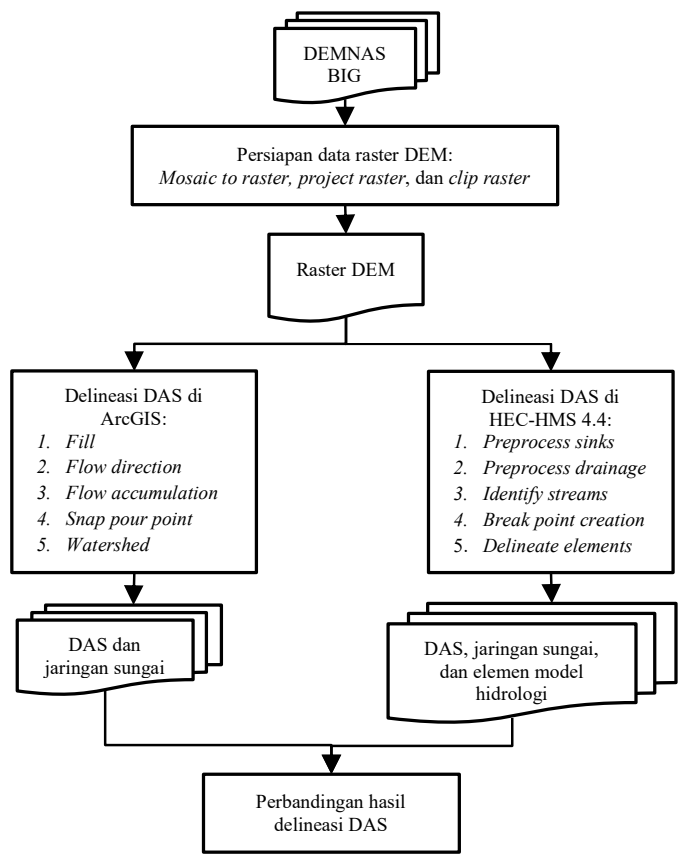

Gambar 1. Bagan alir tahapan penelitian

\section{HASIL DAN PEMBAHASAN}

Tahapan dalam proses delinasi DAS dan model hidrologi di HEC-HMS 4.4 secara garis besar yaitu: 1) pembuatan dan pengaturan Basin Model, 2) pembuatan Terrain Model, dan 3) pemrosesan GIS.

Pembuatan model DAS dilakukan dengan komponen Basin Model Manager. Komponen ini diperlukan untuk merepresentasikan elemen-elemen DAS seperti subbasin, reach, junction, reservoir, sink, dan lain-lain. Adapun pengaturan data elevasi yang akan dihubungkan dengan model DAS dilakukan setelah data terrain dibuat.

Pembuatan data terrain dilakukan melalui komponen Terrain Data Manager. Data DEM yang digunakan sebagai terrain terlebih dahulu diolah dalam perangkat ArcGIS atau bisa menggunakan perangkat GIS lainnya. Proses pengolahan yang dilakukan dalam penelitian ini adalah penggabungan mosaik raster DEM (mosaic to raster), proyeksi 


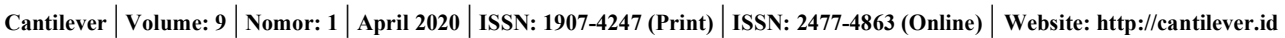
M. Baitullah Al Amin, dkk. / Delineasi DAS dan Elemen Model Hidrologi menggunakan HEC-HMS Versi 4.4

sistem koordinat (project raster), dan pemotongan wilayah kajian (clip). Hal ini dilakukan agar raster DEM yang digabungkan memiliki properti dan band yang seragam, serta menjadi data yang terproyeksi sistem koordinat UTM (Universal Transverse Mercator) pada zona 48S.

Pemrosesan GIS dalam HEC-HMS 4.4 dilakukan secara bertahap yang berurutan, yaitu: 1) coordinate system, 2) preprocess sinks, 3) preprocess drainage, 3) identify streams, 4) break point creation, dan 5) delineate elements. Penetapan sistem koordinat yang digunakan perlu dilakukan agar sama dengan sistem koordinat dari data terrain. Tahapan preprocess sinks dan preprocess drainage dilakukan untuk memperoleh analisis daerah cekungan/ pengisian dan arah aliran. Adapun tahapan identify streams dilakukan untuk menganalisis jaringan sungai (stream network) berikut orde sungai (stream order) yang dibentuk dari akumulasi aliran. Tahapan break point creation dilakukan untuk menentukan titiktitik yang menjadi outlet atau luaran dari suatu DAS. Terakhir, pada tahapan delineate elements dilakukan untuk mendelineasikan batas-batas DAS berikut subbasin dan elemen-elemen model hidrologi. Gambar 2 memberikan berbagai ilustrasi hasil dari masing-masing proses GIS dalam HECHMS 4.4.

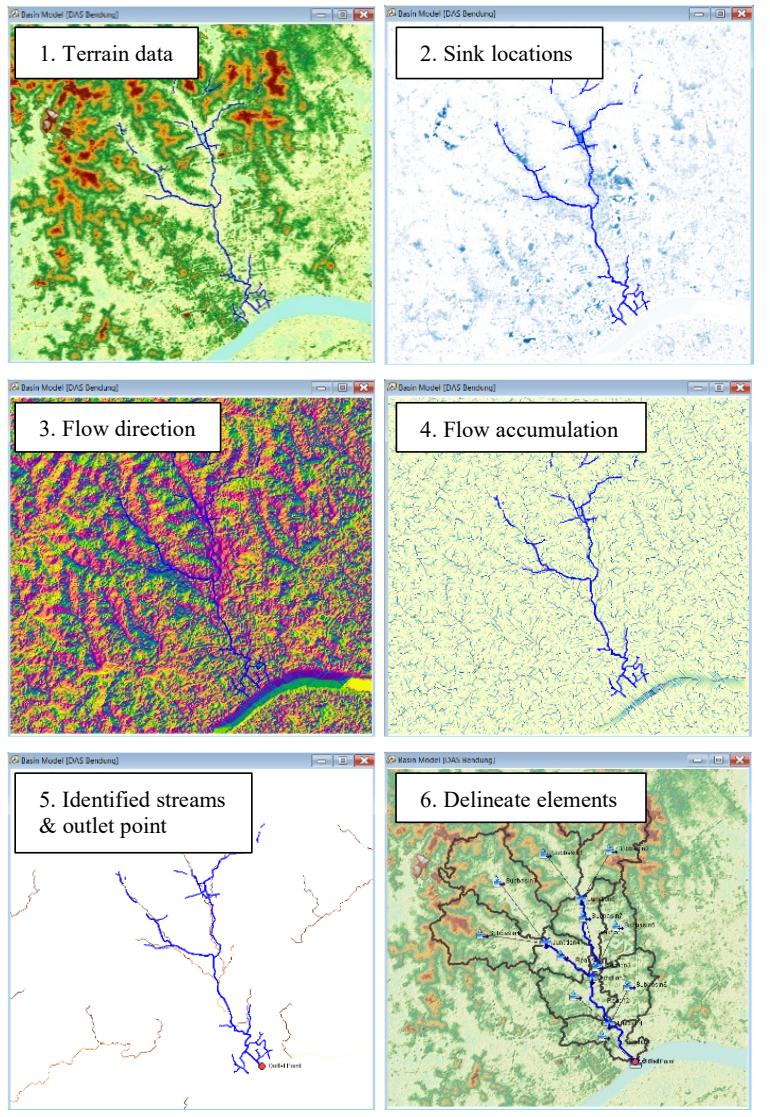

Gambar 2. Ilustrasi tahapan dan proses delineasi DAS dan elemen model hidrologi di HEC-HMS 4.4
Tahapan-tahapan delineasi DAS dalam HECHMS 4.4 di atas secara umum mirip dengan proses delineasi yang dilakukan menggunakan perangkat ArcGIS. Fungsi preprocess sinks dan preprocess drainage mirip dengan fungsi fill dan flow direction dalam analisis hidrologi menggunakan ArcGIS. Hal yang sama juga untuk fungsi identify streams, dimana proses ini mirip dengan fungsi flow accumulation. Adapun fungsi break point creation serupa dengan fungsi snap pour point dan fungsi delineate elements sama dengan fungsi watershed dalam ArcGIS. Seluruh fungsi tersebut dalam ArcGIS diakses melalui menu ArcToolbox. Tabel 1 di bawah ini merangkum perbandingan fungsi delineasi DAS dalam HEC-HMS 4.4 dan ArcGIS.

Tabel 1. Perbandingan fungsi delineasi DAS dalam HEC-HMS 4.4 dan ArcGIS

\begin{tabular}{|c|c|c|c|}
\hline \multirow[t]{2}{*}{ No. } & \multicolumn{2}{|c|}{ Fungsi } & \multirow[t]{2}{*}{ Deskripsi Fungsi } \\
\hline & HMS 4.4 & ArcGIS & \\
\hline 1 & Preprocess sinks & Fill & $\begin{array}{l}\text { Analisis daerah pengisian } \\
\text { dan cekungan }\end{array}$ \\
\hline 2 & $\begin{array}{l}\text { Preprocess } \\
\text { drainage }\end{array}$ & Flow direction & Analisis arah aliran \\
\hline 3 & Identify streams & $\begin{array}{l}\text { Flow } \\
\text { accumulation }\end{array}$ & $\begin{array}{l}\text { Analisis akumulasi aliran } \\
\text { dan jaringan sungai }\end{array}$ \\
\hline 4 & $\begin{array}{l}\text { Break point } \\
\text { creation }\end{array}$ & Snap pour point & $\begin{array}{l}\text { Penentuan titik-titik outlet } \\
\text { dari aliran sungai }\end{array}$ \\
\hline 5 & Delineate elements & Watershed & $\begin{array}{l}\text { Delineasi DAS. Pada HEC- } \\
\text { HMS } 4.4 \text { sekaligus delinease } \\
\text { elemen model hidrologi }\end{array}$ \\
\hline
\end{tabular}

Gambar 3 dan 4 masing-masing memberikan perbedaan hasil delineasi batas-batas DAS dan jaringan sungai antara HEC-HMS 4.4 dan ArcGIS. Perbandingan hasil delineasi DAS pada Gambar 3 menunjukkan bahwa batas-batas DAS yang dihasilkan dari HEC-HMS 4.4 persis sama dengan yang dihasilkan oleh ArcGIS. Hal ini menunjukkan bahwa HEC-HMS 4.4 dapat melakukan delineasi DAS dengan kualitas hasil yang sama baik dengan ArcGIS. Luas sub-DAS Bendung yang dihasilkan adalah 1.837 ha atau $18,37 \mathrm{~km}^{2}$.

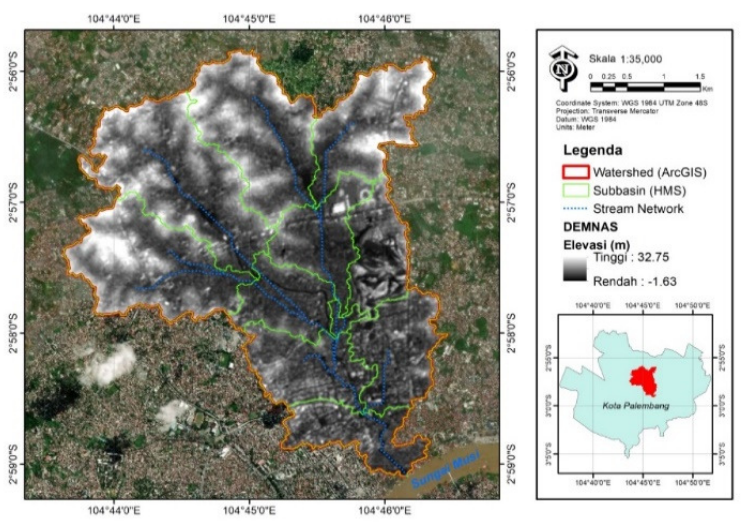

Gambar 3. Perbandingan batas-batas DAS hasil delineasi 


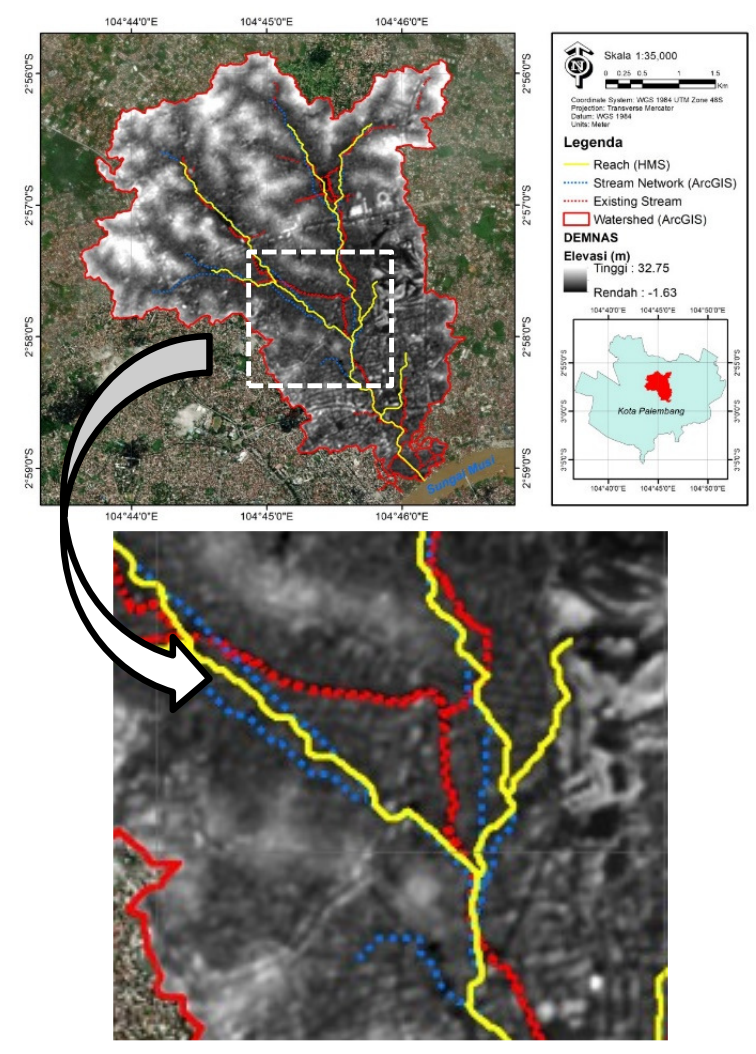

Gambar 4. Perbandingan jaringan sungai hasil delineasi

Adapun perbandingan hasil delineasi jaringan sungai antara HMS 4.4 dan ArcGIS (Gambar 4) menunjukkan adanya sedikit perbedaan, dimana posisi garis aliran yang tidak persis sama di antara keduanya. Hal ini dapat dimungkinkan karena perbedaan luasan nilai piksel atau subbasin yang digunakan untuk mendefinisikan suatu jaringan sungai dalam HEC-HMS 4.4 maupun ArcGIS dan algoritma yang digunakan dalam analisis jaringan tersebut. Jaringan sungai yang dihasilkan dari proses delineasi keduanya juga menunjukkan perbedaan dengan alur sungai eksisting. Hal ini dapat terjadi disebabkan karena kondisi topografi di sekitar subDAS Bendung sudah berubah akibat pembangunan karena berada di pusat kota. Disamping itu, tingkat ketelitian dan ukuran piksel DEM yang digunakan juga dapat mempengaruhi akurasi hasil dari delineasi jaringan sungai. Walau bagaimanapun, kesalahan juga dapat dimungkinkan terjadi sekalipun menggunakan data DEM yang dengan tingkat ketelitian yang tinggi dan resolusi DEM yang lebih baik (Savant et al., 2002). Meskipun demikian, kedua hasil delineasi menunjukkan bentuk jaringan sungai yang mirip dengan arah pengaliran yang serupa. Hal ini menjadi penting mengingat jaringan sungai yang dibentuk oleh HECHMS 4.4 akan mempengaruhi geometri dan karakteristik dari elemen reach yang dimodelkan.

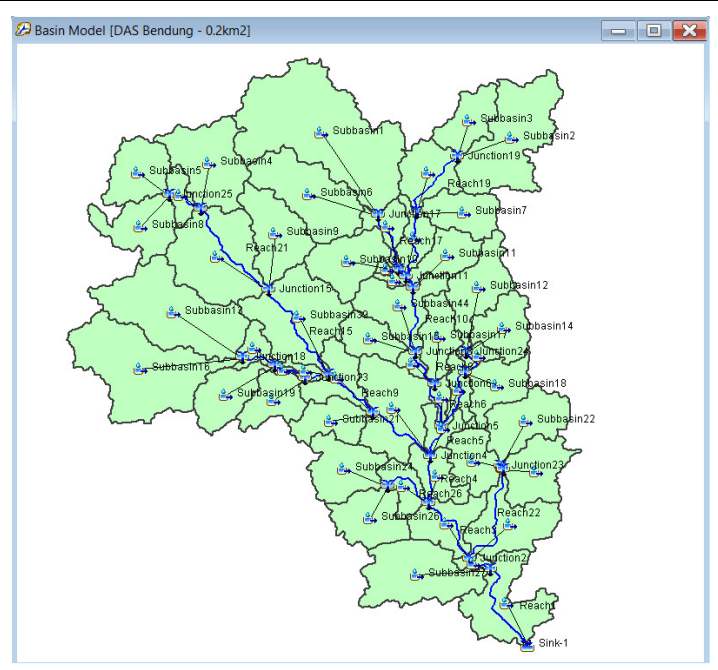

Gambar 5. Hasil delineasi DAS dan elemen-elemen model hidrologi dengan area sub-DAS minimal $0,2 \mathrm{~km}^{2}$

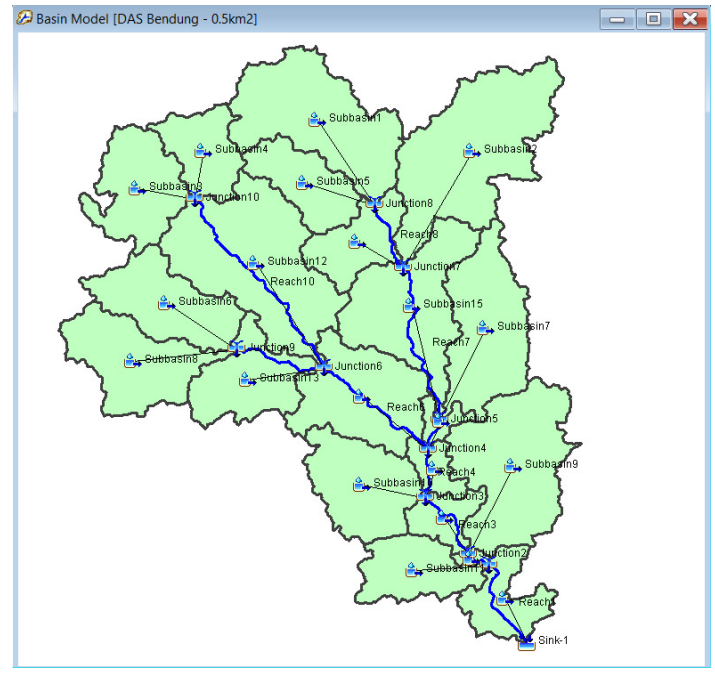

Gambar 6. Hasil delineasi DAS dan elemen-elemen model hidrologi dengan area sub-DAS minimal $0,5 \mathrm{~km}^{2}$

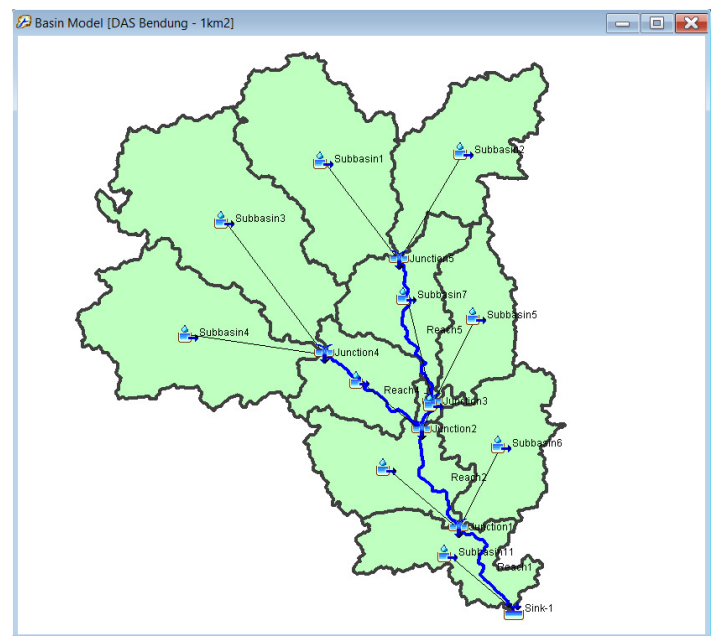

Gambar 7. Hasil delineasi DAS dan elemen-elemen model hidrologi dengan area sub-DAS minimal $1,0 \mathrm{~km}^{2}$ 


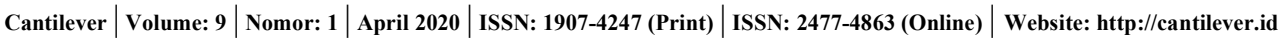

M. Baitullah Al Amin, dkk. / Delineasi DAS dan Elemen Model Hidrologi menggunakan HEC-HMS Versi 4.4

Perbandingan jumlah elemen-elemen model hidrologi yang didelineasi dari berbagai nilai luasan sub-DAS minimal ditunjukkan dalam Gambar $5-7$ dan dirangkum dalam Tabel 2. Dari gambar-gambar tersebut terlihat bahwa semakin kecil luasan subDAS minimal yang ditetapkan dalam mendefinisikan suatu subbasin, maka akan dihasilkan jumlah elemen hidrologi yang semakin banyak dengan skematisasi yang semakin kompleks. Hal ini disebabkan karena nilai luas sub-DAS yang lebih kecil akan membagi subbasin dengan luasan yang lebih kecil dan dalam jumlah yang lebih banyak. Hal ini juga akan berdampak pada jumlah elemen lain (reach dan junction) yang mengikutinya.

Tabel 2. Perbandingan jumlah elemen model hidrologi dari berbagai hasil delineasi

\begin{tabular}{cccccc}
\hline \multirow{2}{*}{ No. } & $\begin{array}{c}\text { Area sub-DAS } \\
\text { minimal }\left(\mathrm{km}^{2}\right)\end{array}$ & \multicolumn{4}{c}{ Elemen } \\
\cline { 3 - 6 } & 0,2 & 53 & 25 & 26 & 1 \\
\hline 1 & 0,5 & 21 & 10 & 10 & 1 \\
2 & 1,0 & 11 & 5 & 5 & 1 \\
3 & & & & &
\end{tabular}

Meskipun jumlah elemen yang disajikan dalam Tabel 2 di atas bisa sangat bervariasi dan tidak baku dimana tergantung pada kondisi dari terrain wilayah yang dikaji, namun hasil delineasi tersebut telah menggambarkan tingkat ketelitian model hidrologi yang akan dicapai. Semakin banyak jumlah elemen, maka tingkat akurasi model akan semakin baik, begitupun sebaliknya. Namun, waktu dan upaya yang diperlukan untuk membuat model yang lebih detil juga akan semakin bertambah.

Hadirnya HEC-HMS 4.4 ini akan memberikan kemudahan bagi penggunanya dalam mendelineasikan DAS berikut elemen-elemen model hidrologi. Pemrosesan GIS untuk delineasi DAS dapat dilakukan tanpa memerlukan perangkat GIS lainnya seperti yang selama ini dilakukan. Disamping itu, elemen-elemen hidrologi dari model DAS dapat secara otomatis terbentuk bersamaan dengan proses delineasi DAS sehingga model hidrologi yang detil dengan tingkat ketelitian yang tinggi akan dapat lebih mudah dicapai.

\section{KESIMPULAN}

Berdasarkan hasil dan pembahasan sebelumnya maka dapat disimpulkan bahwa fasilitas baru untuk pemrosesan GIS yang disematkan dalam HEC-HMS versi 4.4 sangat membantu dalam delineasi DAS dan elemen-elemen model hidrologi. Jika dalam versi sebelumnya elemen-elemen tersebut dibuat secara manual, maka dalam versi terbaru ini objek tersebut dapat dibuat secara otomatis. Hal ini setidaknya memungkinkan untuk menghindari kesalahan pemodelan oleh pengguna, mempersingkat waktu penyusunan model yang rumit dan besar, dan mempermudah bagi pengguna dengan pengalaman GIS yang terbatas.

Hasil delineasi DAS dari perangkat HEC-HMS 4.4 menunjukkan hasil yang serupa dengan delineasi yang dihasilkan dalam ArcGIS. Hal ini menunjukkan bahwa tingkat akurasi dan kualitas delineasi yang dicapai adalah sangat baik. Dengan demikian, proses delineasi DAS telah dapat digantikan hanya dengan menggunakan HEC-HMS 4.4 saja. Hal ini memberikan keuntungan dimana pengguna dapat mengurangi biaya untuk membeli perangkat GIS yang bersifat komersial atau berbayar. Oleh karena perangkat HEC-HMS 4.4 bersifat public domain, yaitu gratis untuk digunakan, maka pemanfaatannya harus didorong untuk berbagai keperluan analisis dalam proyek di bidang sumberdaya air. Pengembangan fasilitas GIS dalam perangkat ini perlu terus dilakukan sehingga fungsinya menjadi lebih lengkap untuk berbagai fungsi yang mendukung penggunaannya.

\section{REFERENSI}

Bhatt, J. P. \& Pandya, P. H. (2014). Application of HECGeoHMS as a Tool of Hydrologic Modeling in the Field of Water Resources Engineering. IJSRD, 1(11), 2486-2488.

Eljack, I. H., Elhag, A. R., \& Elsheikh, R. F. (2015). Streamflow Analysis using GIS Techniques and HECGeoHMS. International Journal of Engineering Inventions, 5(1), 5-13.

Flemming, M. J., \& Doan, J. H. (2013). HEC-GeoHMS Geospatial Hydrologic Modeling Extension User's Manual Version 10.1. U.S. Army Corps of Engineers, Hydrologic Engineering Center. Retrieved from https://www.hec.usace.army.mil/software/hecgeohms/documentation/HECGeoHMS_Users_Manual_10.1.pdf

Gunawan, G. (2011). Deliniasi DAS Berbasis Sistem Informasi Geografis dalam Rangka Mendukung Pengelolaan DAS Terpadu. Inersia: Jurnal Teknik Sipil, 3(1), 7-15.

Ilham, U., Prasetyo, Y., \& Sabri, L. (2020). Analisis Spasial Aliran Lahar Menggunakan HEC-HMS dan HEC-RAS pada Kali Gendol-Opak Kawasan Gunung Merapi. Jurnal Geodesi Undip, 9(1), 20-28.

Islam, R. (2004). A Review on Watershed Delineation Using GIS Tools. In The 2nd Asia Pacific Association of Hydrology and Water Resources (APHW). Singapore. Retrieved from http://rwes.dpri.kyotou.ac.jp/ tanaka/APHW/APHW2004/proceedings/OHS/56OHS-A558/56-OHS-A558.pdf

Iswari, M. Y., \& Kasih, A. (2018). DEMNAS : Model Digital Ketinggian Nasional untuk Aplikasi Kepesisiran. Oseana, $X \operatorname{LIII}(4), 68-80$.

https://doi.org/https://doi.org/10.14203/oseana.2018.Vol.4 3 No.4.2

Oleyiblo, J. O. \& Li, Z. (2010). Application of HEC-HMS for Flood Forecasting in Misai and Wan'an Catchments in China. Water Science and Engineering, 3(1), 14-22. https://doi.org/10.3882/j.issn.1674-2370.2010.01.002

Savant, G., Wang, L., \& Truax, D. (2002). Remote Sensing and Geospatial Applications for Watershed Delineation. In ISPRS Comission I Mid-Term Symposium in conjunction with Pecora 15/Land Satellite Information IV Conference 
M. Baitullah Al Amin, dkk. | Delineasi DAS dan Elemen Model Hidrologi menggunakan HEC-HMS Versi 4.4

Integrated Remote Sensing at the Global, Regional and Local Scale (pp. 1-7). Denver, USA: International Society for Photogrammetry and Remote Sensing.

Strapazan, C. \& Petrut, M. (2017). Application of Arc Hydro And HEC-HMS Model Techniques for Runoff Simulation in The Headwater Areas of Covasna Watershed (Romania). Geographia Technica, 12(1), 95-107. https://doi.org/http://dx.doi.org/10.21163/GT_2017.121.10

Sutisna, A. S., \& Putro, H. (2018). Evaluasi Tingkat Akurasi
Digital Elevation Model (DEM) SRTM dan ASTER GDEM dalam Pemodelan Daerah Aliran Sungai ( DAS ) Ciliwung. Media Komunikasi Teknik Sipil, 24(2), 105-112. https://doi.org/https://doi.org/10.14710/mkts.v24i2.17541

Tassew, B. G., Belete, M. A., \& Miegel, K. (2019). Application of HEC-HMS Model for Flow Simulation in the Lake Tana Basin: The Case of Gilgel Abay Catchment, Upper Blue Nile Basin, Ethiopia. Hydrology, 6(1), 1-17. https://doi.org/https://doi.org/10.3390/hydrology6010021 